\title{
ANALYSIS OF EXISTING TRAILERS' CONTAINER LOCK SYSTEMS
}

\author{
Semwogerere Twaibu ${ }^{1 *}$, Byamugisha Nathan ${ }^{2}$, Matovu Davis ${ }^{3}$, Ocen Gilbert ${ }^{4}$, \\ Namwanje Sophie ${ }^{5}$ \\ ${ }^{1-5}$ Computer Engineering Department, Busitema University \\ ${ }^{5}$ Faculty of Management Studies, Islamic University in Uganda
}

\begin{abstract}
Trailers carry large containers to various destinations in the world. These are manually locked on to trailers as they move through these long distances. Security mainly refers to the safety of a state, organization, property, and individuals against criminal activity. The study was made to analyze the existing trailer locks and the insecurity being experienced currently. The study also focused on creating a background to building an automated lock system for auto-mobiles. Findings showed that there are various container types like the General Purpose containers, the Hard-Top containers and the Open-Top among others. Similarly, the twist locks were the ones revised for this study. The study also discussed the weaknesses of the twist locks, most especially the non-notification on unsecured locks. This causes leads to accidents and wastage of lives and property. The study finally proposed an automated lock system to overcome these weaknesses to some good extent.
\end{abstract}

\section{KEYWORDS}

Accidents, Automated Lock System, Container, Security, Trailer.

\section{INTRODUCTION}

Most luggage that is imported in various countries is carried in containers. These are locked and carried on the trailer cars. Cartons, crates, wooden cases, palletized cargo, drums, plastic cans, sacks and bales, rolls and coils, steel plates, vehicles, sheets of glass, wet hides and skins, liquids, bulk freight, long cargo and live animals are some of the contents in the containers. [1].

The security and safety of the container as it travels from place to place and before it leaves for its destination mainly depends on the trailer driver to check whether the container is fully locked or not. Surprisingly from time to time containers fall off the trailers due to many reasons like insecure locks and over speeding. Insecure locking is mostly a result of the drivers failing to physically check the locks, and the lack of secure lock system displayed in the cabin. Several scenarios from around the world where accidents from insecure locks have been identified. Three cases have been highlighted:

On Monday, April 20 ${ }^{\text {th }} 2015$, in Dubai, United Arab Emirates, two containers loaded with paint fell off the truck on a main road called Al Muhaisana, though no one was injured. These damaged

DOI : $10.5121 /$ ijcseit.2018.8401 
the road surface, road signs and symbol boards [2]. In another incident, one person reportedly killed after a shipping container fell on the top of a truck on the north east side of Oklahoma City. The second person who was in the car was rushed to hospital for immediate attention [3].

On Wednesday, $2^{\text {nd }}$ September 2015, a container fell off from a trailer while crossing the bridge at Ojuelegba in Nigeria. This instantly killed two people in a car below the bridge [4]. Similarly, in October 2014, a container fell off a trailer which was heading to Kampala at Bweyogerere on the Jinja highway road. Nobody was killed or injured in this incident [5].

\section{METHODS AND MATERIALS}

\subsection{Observation}

In the verge of acquiring information, direct observation on how the different procedures about container locking were used. This observation was done at different places where trailers normally park or pass. For this study, I used places like the checkpoints of Busitema Revenue/weighing bridge point, Malaba and Busia Boarders, Tororo, and Kampala Industrial area.

\subsection{Literature Review}

It involved reading a vast number of pieces of literature. These were largely from different informative sources like internet, books, journals, and newspapers [1], ..., [5], among others. The literature was about the containers, trailers and the lock monitoring systems. The information necessary for the identification and analysis of the requirements needed to accomplish the implementation of the system. It should be noted that container shipping, for example has been in use for over 60 years now, although, transportation of goods and services has been on-going for several centuries now [6][7][8]. The efficiency of such transportation has been improving ever since up to the "Inter-modalism" level [8]. Inter-modalism is a system that is based on the theory that efficiency will be vastly improved when the same container, with the same cargo, can be transported with minimum interruption via different transport modes, to the final delivery points [8]. The modes of transport include the trailer mode on land, and the ship mode on water. The systems identified in the literature do not include automated lock systems alert which has led to several containers falling of the trailers.

The collected data was thoroughly analyzed basing on the aim of the study. The analysis of all the relevant information and interpretation of the data depended on the historical transformation of container locks up to the automated possibility therein. The analysis was also targeting the automation process in the forth coming manuscript. Therefore, the study aimed at studying the inherent weaknesses of the existing monitoring method for Trailer Container locks and to identify the requirements necessary for designing the user interface for the automated type. It involved developing a hardware module for the proposed Trailer Container lock monitoring system in the next study. 


\section{FINDINGS}

\subsection{Container Types and their Lock Systems}

A trailer container is a container with strength to withstand shipment, storage and handling. It is designed to be moved from one mode of transport to another without unloading and reloading.

\subsubsection{Types of Containers}

General Purpose Container: Freight container, totally enclosed and weatherproof, having a rigid roof, rigid side walls, rigid end walls and a floor, having at least one of its end walls equipped with doors and intended to be suitable for the transport of cargo of the greatest possible variety [9]. There are two types of general purpose containers that is: General purpose container 20', 40' feet.

High Cube General Purpose Container: Especially for light, voluminous cargo and over height cargo up to max $2.70 \mathrm{~m}\left(8^{\prime} 10\right.$ 1/4") [10]. It has numerous lashing devices on the top and bottom longitudinal rails and the corner posts. Lashing devices have a permissible load of $1000 \mathrm{~kg}$ (2 $205 \mathrm{lbs}$.) each. Consider over height for inland transportation. It has permissible weight limits for road and rail transport.

Hardtop Container 20', 40': It has especially been constructed for heavy loads, high and excessively high loads and for loading, e.g. by crane through roof opening and door side, the steel roof of some series is fitted with fork-lift rings so that it can be removed by using a forklift [11]. The weight of the steel roof is approx. $450 \mathrm{~kg}$ (990lbs.). With the roof removed and the doorheader swung out, it is much easier to load cargo using a crane via the door side.

Open Top Container 20', 40': Especially for over height cargo, loading from top side, e.g. by crane, loading from door side, e.g. with cargo hanging from overhead tackle [12]. Door header can be swung out on all open top containers. If required, disposable tarpaulins can be provided. For fastening tarpaulins, lashing bars are available on the outside of the walls. Using one way tarpaulins requires the corner castings to be accessible. Fork-lift pockets are available on a number of containers. The capacity of the floor for use of fork-lift trucks exceeds the ISO standard by $33 \%$ on all $20^{\prime}, 40$ ' open top containers.

Flat Container 20', 40': This was designed for heavy loads and over-width cargo. It has a strong bottom construction with fixed end walls (which allow bracing and lashing of cargo as well as stacking). Gooseneck tunnel on both ends of all 40' flats. It has numerous very strong lashing devices on the corner posts, longitudinal rails and on the floor. Lashing devices on the longitudinal rails of 20 ' containers have a permissible load of $2.000 \mathrm{~kg}$ or $4.000 \mathrm{~kg}$ respectively (4.410 lbs. or 8.820 lbs. respectively) each [13].

Super Ventilated Container 20': Especially designed for cargo, which needs ventilation. Natural ventilation is provided by openings in top and bottom longitudinal rails [14]. The labyrinth construction of these ventilation openings ensures weather- proofers. It also has numerous lashing devices on the top and the bottom longitudinal rails and the corner posts. Lashing devices have a permissible load of $1000 \mathrm{~kg}$ (2 $205 \mathrm{lbs}$.) each. 
International Journal of Computer Science, Engineering and Information Technology (IJCSEIT), Vol.8, No.4, August 2018

Insulated Container 20', 40': Especially for cargo, which needs constant temperatures above or below freezing point, walls in "sandwich-construction" with Polyurethane foam to provide maximum insulation, temperature is controlled by ships /terminal's cooling plant or "clip-on-unit [15]. The air, delivered at the correct temperature, is circulated in the container through two apertures in the front wall (supply air via the lower aperture, return air via the upper aperture). Possible temperatures inside the 20' containers, depending on the specification of respective cooling device from about $+12{ }^{\circ} \mathrm{C}$ to $-25^{\circ} \mathrm{C}\left(+54^{\circ} \mathrm{F}\right.$ to $\left.-14^{\circ} \mathrm{F}\right)$. It was noted that the maximum stowage height in below table and as indicated by the red line inside the container in order to ensure proper ventilation [8][9].

\subsubsection{Lock Systems}

Twist lock are the main locking system for securing freight containers to the trailers on which they are transported. There are various types of twist locks but this study sub divided them into two groups: the retractable and non-retractable twist locks [16]. These are briefly described in the following sub-sections.

Retractable Twist lock Type WCI 151/2,WCI 151/3: Designed to secure ISO and special containers to rigid, skeletal and platform vehicles/chassis. Allows non-containerized loads to be carried by retracting below deck level, it has a cost effective fabricated steel body and is designed for interchangeability of spare parts [17].

Retractable Screw down Twist lock Type WCI 162 RSB, WCI 148 RS: A fully retractable screw down twist lock designed specifically for demountable applications [18]. The head can be raised with the container in position and will screw down onto any thickness aperture plate. It is available with weld on or bolt on back plate. It is simple to operate.

Non-Retractable Twist lock Type WCI 149 2NR: A non-retractable twist lock simply fitted to vehicle/chassis. The securing head remains permanently proud of the deck for loading containers in the shortest possible time [19]. It has a weld able cast steel body and is designed for interchangeability of spare parts.

Non-Retractable Screw down Twist lock Type WCI 149 NRS: The securing head remains permanently proud of the deck for loading containers in the shortest possible time. The screw down facility and an optional vertical bolt ensures safety for loads during transportation [20] [21] [22].

\section{DISCUSSION}

There are various lock systems that have been identified in this study, with particular emphasis on the twist lock system. Apart from these locks being manual, there is still no real-time alert system in case of a problem with the lock. Whereas carriers included the ships and trailers, emphasis was on the trailers in this study. Containers that fall off cause huge damage and accidents on roads. There was a need to retrieve such information about locks that are available in order to develop a better lock system that will reduce the risks.

It was noted that the current monitoring methods for Trailer Container locks have a weakness that the lock status cannot be monitored in real time. In this case, a container can get unlocked and the 
trailer driver will never get to know until the container has fallen off the trailer. There is therefore need to design a system that can notify the trailer driver about the status of the container locks in real time that is before driving and also when the driver is driving the trailer truck. It is expected to enable the trailer driver to know the status of the locks in real time. The system should be able to notify him in case any of the locks on the container is not secure. The design shall in a way fail the start if there is a problem with locks. A buzzer shall sound and the trailer driver can check the display and knows which lock has a problem. The following block diagram explains the working of the proposed for the new system.

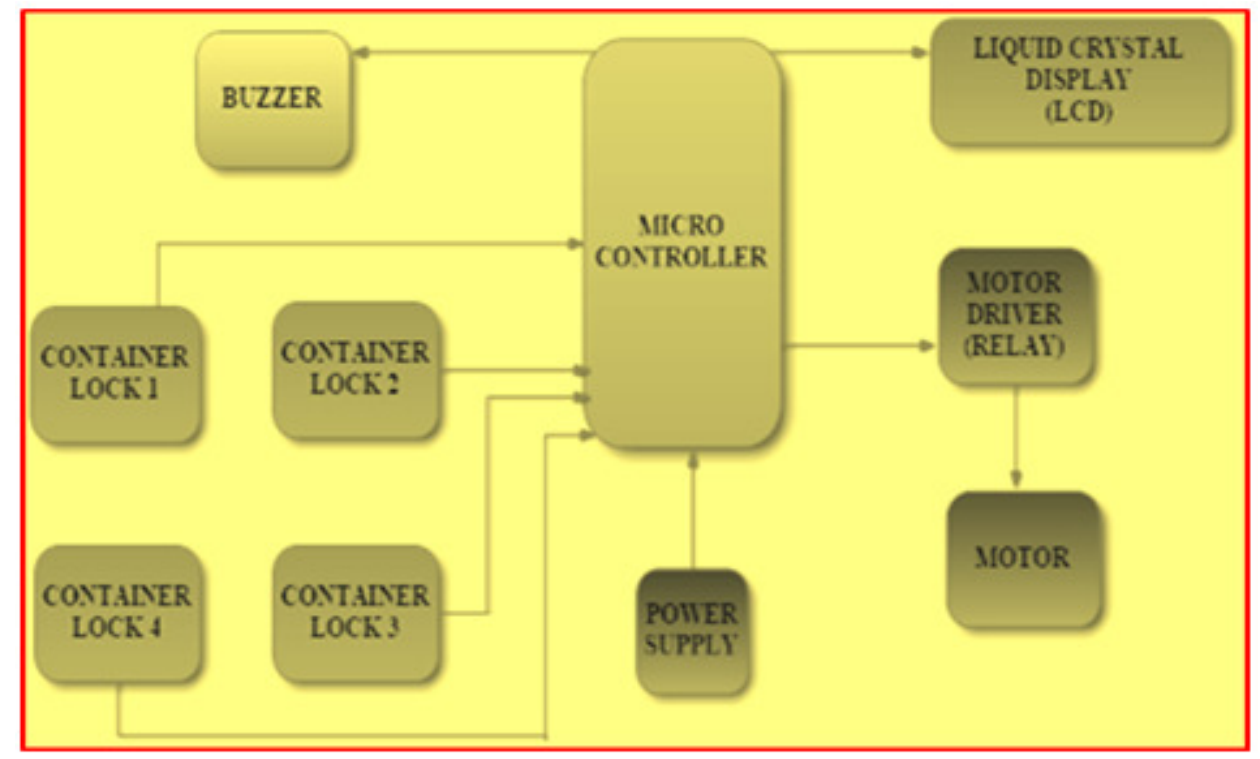

Figure1: Proposed Block Diagram for the Proposed System

\section{Conclusion}

There are various container locks that are currently in use. The study aimed at identifying the existing locks so as to be able to come up with an automated process of handling locks regarding containers on trailers. Therefore, several lock types were reviewed basing on the weaknesses and strengths they might have. The review was also meant for creating a strong background to a realtime monitoring system of container locks on trailers. This monitoring system can really be of help in curbing such accidents like containers falling off trailers.

\section{REFERENCES}

[1] Hinkelman, E .(2005). Manley and Shippey, Importers Manual USA.

[2] Sathish, V. (2015). "Emirates 24/7 News," Dubia.

[3] Nuttle, M. (2014). "News9.com," Oklahoma.

[4] Usman, E. (2015). "Vanguard," 3 killed as Container lands on Vehicles, Lagos.

[5] Uganda Police Information. (2014). "Traffic flow updates," Kampala. 
International Journal of Computer Science, Engineering and Information Technology (IJCSEIT), Vol.8, No.4, August 2018

[6] Essery, R. J, Rowland. D. P. \& Steel W. O. (1979). British Goods Wagons from 1887 to the Present Day. Augustus M. Kelly Publishers. New York USA. Page 92

[7] Lewandowski, K. (2015). "Benjamin Franklin Fitch the Forgotten Developer of the Container System in US of America". Global journal of Human Social Science. H, Interdisplinary. 15 (8): 39-48. ISSN 0975-587X.

[8] Lewandowski, K. (2014). "Stanislaw Rodowicz, Eng. The Forgotten Pioneer of Containerization in Poland". Logistics and Transport. 23(3): 73-78. ISSN 1734-2015.

[9] Silvers, F. (2008). Building and Maintaining a Data Warehouse, 2008.

[10] Branch, E. (2012). Elements of Shipping: 7th Edition.

[11] Hinkelman, E. (2005). Dictionary of International Trade: Handbook of the Global Trade Community.

[12] Brodie, P. (2013). Illustrated Dictionary of Cargo Handling.

[13] Branch, A. (2013). Export Practice and Management.

[14] Nemerow, N. (2009). Environmental Engineering.

[15] Noteboom, T. (2011)). Current Issues in Shipping, Ports and Logistics.

[16] Van Ham, H \& Rijsembrij, J. (2012). Development of Containerization. Amsterdam: IOS Press. P. 8, ISBN 978-1614991465. Retrieved July, 2015.

[17] Levinson, M. (2006). The Box: How the Shipping Container Made the World Smaller and the World Economy Bigger. Pricenton, N. J.: Pricenton University Press. P. 127, ISBN 0-691-12324-1. Retrieved July, 2015

[18] Heins, M. (2013). The shipping Container and the Globalization of American Infrastructure. University of Michigan, p. 15.

[19] Sclater, N. (2011). Mechanisms and Mechanical Devices Sourcebook, 5th Edition.

[20] Lowe, D. (2008). Dictionary of Transport Logistics.

[21] Phillips, B. (2005). The Complete Book of Locks and Locksmithing. Seventh Edition, ISBN-13:97 80071448291, Mc Grawhill.

[22] Frank, B. (2002). The Globalization of the Oceans. International Maritime Economic History Association. ISBN 0-9730073-3-8-Containerization from the 1950's to the Present. 


\section{AUTHORS}

Dr. Twaibu Semwogerere holds a Bachelor of Science Education degree (Mathematics), Master of Science degree (Applied Mathematics) and a $\mathrm{PhD}$ in Mechanical Engineering (Engineering Mathematics) of Makerere University, Kampala, Uganda. He has a work experience of over 22 years in colleges and university teaching. Published several papers, the previous one being: "Spatiotemporal Predictions using Multivariate Singular Spectrum Analysis in the journal Afrika Statistika Vol. 13 (1), 2018, pages 1483-1493" as a co-author. He is currently a Senior Lecturer in the Faculty of Engineering, Busitema University.

Byamugisha Nathan graduated from Busitema University with a Bachelor's degree in Computer Engineering. Nathan has deep knowledge and interest in network Engineering and software development.

Mr. Matovu Davis is a Lecturer at the department of Computer Engineering, $\mathrm{He}$ holds BSc \& MSc in Computer Systems and Networks Engineering from KHNURE, $\mathrm{He}$ is currently pursuing a PhD at MMUST-Kenya, his research interests are in cyber security and Internet of things

Mr. Gilbert Ocen is a Lecturer at the department of Computer Engineering, He holds BSc. (Hons) in Computer Engineering from KHNURE, MSc. Information Technology- from CUU and he is Currently Pursuing a PhD at MMUST-Kenya. He has deep research interest in information and Network security, Cyber-security and Digital Forensics as well as ICT4D. He has supervised over 40 under graduate research projects in his areas of interests

Ms. Namwanje is a young researcher at the Islamic University in Uganda where she is finalising on her Master's Degree in Islamic Banking and Finance (Business Management). Her Last Co-Publication was "Analytical Security with Lock Systems which was presented at the 1st Pan African International Research Congress in June, 2018, in Kisumu.
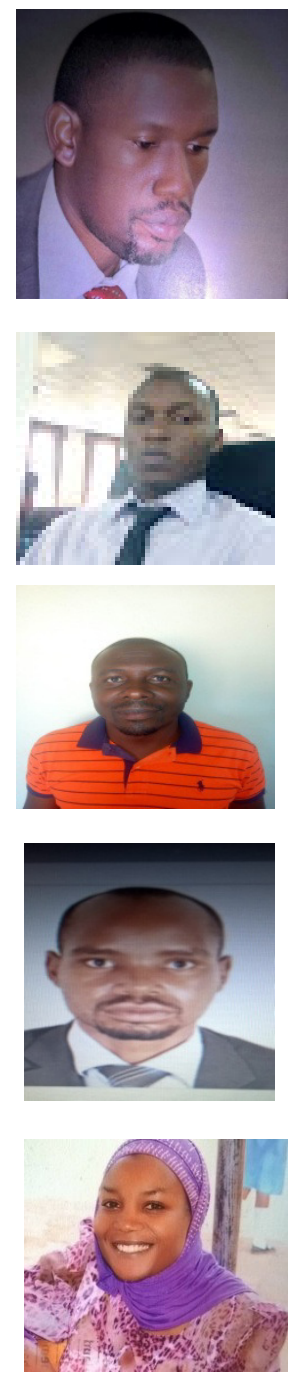